\title{
Optimal Configuration Algorithm for Mechanical Products Based on the Constraint of Carbon Footprint
}

\author{
Wei Bo ${ }^{*}, 1$, Li Renwang ${ }^{2}$, Zheng Hui ${ }^{1}$, Chen Gang ${ }^{1}$ and Zong Xianliang ${ }^{1}$ \\ ${ }^{I}$ College of Mechanical Engineering, Tianjin University of Science and Technology, Tianjin, 300222, P.R. China \\ ${ }^{2}$ Faculty of Mechanical Engineering and Automation, Zhejiang Sci-Tech University, Hangzhou, 310018, P.R. China
}

\begin{abstract}
The concept of carbon footprint controllable product is proposed to assess carbon footprint during the stage of product development and configuration. It's different from carbon footprint assessment afterwards. As a result, the control objectives can be quantified accurately and realized easily. Relations among product characteristics, which include carbon footprint, are uncertain. In order to obtain the optimal product configuration scheme based on constraint of carbon footprint, three-stage theory is proposed. These three stages refer to functional configuration, compliance evaluation of carbon footprint, and optimal comprehensive evaluation. Using this theory, functional feasible solution set, carbon footprint conforming set and the optimal scheme are generated respectively. Grey relation analysis is verified as an effective method for comprehensive benefit evaluation. Reducer design is used as a case study to illustrate the proposed concept.
\end{abstract}

Keywords: Product configuration, Carbon footprint, Grey relation analysis, Multi-objective decision-making.

\section{INTRODUCTION}

Carbon footprint (CFP) can be divided into four types: national carbon footprint, enterprise carbon footprint, personal carbon footprint, and product carbon footprint. Recently, more and more concerns and attention have been paid to the last categorization, i.e. product carbon footprint.

Carbon footprint label is the manifestation of product carbon footprint to show the amount of greenhouse gas emissions during all processes, including production, transportation, sales stage, sometimes also including use stage and final disposal stage. One of the purposes of carbon footprint label is to make enterprises better communicate with consumers about enterprise's efforts in energy conservation and carbon emissions reduction, as well as carbon footprint. Consequently, consumers are able to compare products among different manufacturers. In recent years, low carbon product standards have developed rapidly. The trend has the potential to evolve into a wide range of green trade barriers, rationality in surface, legality in form, widespread in content, and concealment in implement.

The concept of Carbon Footprint Controllable Products is proposed to meet the external demands such as "carbon tariffs", other international trade barriers, consumer preference, and government requirements. This concept can also help enterprises to increase consuming efficiency of energy and resources, improve production process, and reduce cost etc., with the prices of energy and raw materials rising quickly. Because carbon footprint is closely related to greenhouse emission, more and more partners worldwide including manufacturers, consumers, governments and environmental groups put more attention to product carbon footprint. Many

*Address correspondence to this author at the College of Mechanical Engineering, Tianjin University of Science and Technology, Tianjin, 300222, P.R. China; Tel: 18920203303; E-mail: weibotj@163.com studies have been conducted in the related fields. The main progresses focus on:

\subsection{Low Carbon Manufacturing and Design Technology}

Rapid Manufacturing (RM) is regarded as the low carbon manufacturing technology of the future [1]. Scipioni et al. have proposed a method, which can identify main processes contributing to climate change in enterprise production and supply chain [2]. Rahimifard et al. have proposed a general conceptual and computational framework for the efficiency evaluation of the manufacturing processes [3]. Alsaffar et al. highlighted the importance of reducing carbon footprint through simultaneous consideration of manufacturing processes and supply chain activities [4]. Bao et al. constructed a multi-constrained objective optimization model to obtain the most reduction of carbon emission through low-carbon design improvement of key modular units [5].

\subsection{Low Carbon Supply Chain}

To bring carbon footprint management into supply chain, the tradeoff among cost, service, quality and carbon emission must be achieved by coordination of supply chain in product, process, information and capital [6]. A multi-objective mixed integer programming model is used to integrate carbon emissions and the total cost of logistics supply chain into design process, the effects of carbon trading right to supply chain design are also taken into account[7]. Ingram and Dewayne acquire product carbon footprint data through applying EPC to supply chain of enterprise product, tracking and monitoring the products' carbon emissions from production, storage, distribution, transport and consumption [8].

\subsection{Verification of Product Carbon Footprint}

A large number of research have focused on carbon footprint calculation and verification methods for specific prod- 


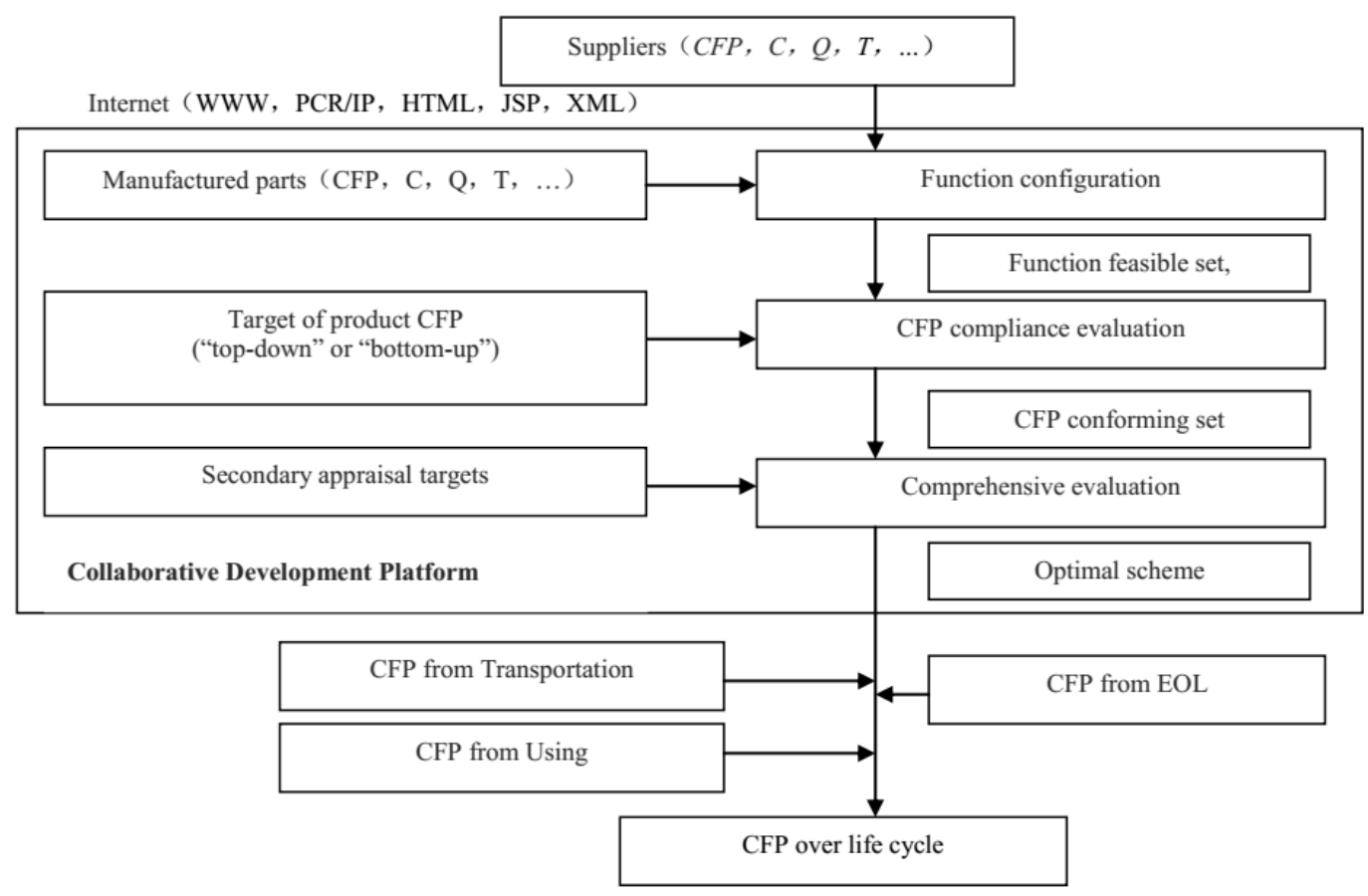

Fig. (1). The collaborative research and development framework of CFP controllable product.

ucts in many different fields such as plastic, wood, and hotel [9-12].

In fact, carbon footprint over product life cycle only represents one attribute of a product. Only after enterprises consider all aspects including cost, quality and many other factors during product design and configuration, can they make the right decision. Especially, reducing carbon footprint may deteriorate other indicators, such as cost, due to the inherent relations among these factors. Hence, as a whole, carbon footprint of products is not the smaller the better. Core enterprises should match carbon footprint with other relevant indicators, and control carbon footprint at a reasonable level, such product can be called "carbon footprint controllable products". Product carbon footprint planning is a multiobjective decision problem based on constraint of carbon footprint.

\section{CONFIGURATION STRATEGY AND ALGO- RITHM OF CFP CONTROLLABLE PRODUCT}

Traditional product configuration only needs to meet functional requirements from customers. Now the configuration scheme must also control product carbon footprint. Carbon footprint controllable product requires quantifiable carbon emission evaluation during design stage according to the specified standard. Hence, carbon footprint of the final product can be realized within an acceptable margin of error. Certainly, it is necessary to make a tradeoff among factors such as cost, quality, delivery time, etc.

\subsection{Collaborative R\&d Framework of CFP Controllable Product}

From the viewpoint of Life Cycle Assessment (LCA), product carbon footprint consists of "imported" carbon footprint from supply chain (raw materials and components), carbon footprint from core manufacturing enterprise, logistics carbon footprint, carbon footprint from consuming and EOL (End of Life). Fig. (1) illustrates collaborative research and development framework of CFP controllable product.

Carbon footprints from transportation, consuming, EOL are influenced by many uncertain factors. Relevant accurate databases are hard to obtain. Usually, what core enterprises are able to control include choosing raw materials, selecting suppliers, and controlling manufacturing processes. Therefore, configuration algorithm is essential to the proposed carbon footprint controllable product development. As shown in Fig. (1), the configuration process includes three stages: function configuration, carbon compliance evaluation, and comprehensive benefit evaluation. The function feasible solution set, carbon footprint conforming set and optimal scheme are generated after the above-mentioned three stages.

How to set a reasonable target for product carbon footprint? If clients have requirements for carbon footprint, it should be satisfied as much as possible. If clients have not come up with specific requirements, the industry standard should be followed instead. In addition, core enterprises can also set a competitive carbon footprint standard using a "topdown" or "bottom-up" method to embody their social responsibility, to fulfill the preferences of environmental conscious customers as well.

Why is it emphasized that the above-mentioned processes are on a collaborative development platform? The next section of this paper is based on the premise that core enterprises can obtain supplier's real-time information such as price, quality, delivery time, carbon footprint indexes conveniently, for instance, through Internet. Supported by supplier rating system, core enterprises can create an index database of product components and parts. This database is vital for sub- 
sequent evaluation for product configuration schemes. Therefore, product development process of core enterprise is actually a collaborative development process accompanied by continuous information exchange with suppliers.

\subsection{Configuration Algorithm}

Grey Relationship Analysis (GRA) aims at analyzing the relationships in behavior, posture, and boundary. Different from traditional mathematical analysis, GRA provides a simple scheme to analyze the series relationships or the system behavior, even if the given information is insufficient. In fact, it is a holistic comparison method with reference system [13]. In the early stage of product design and development, product's attributes, including carbon footprint, are fuzzy. Therefore, an acceptable result can be drawn using GRA.

Definition 1: Product characteristic (indicator) series. Characteristic information of an object part $i$ can be expressed as :

$$
x_{i}^{\prime}=\left(x_{i}^{\prime}(1), x_{i}^{\prime}(2), \mathrm{L}, x_{i}^{\prime}(k)\right)
$$

therefore, commonly used indicators for mechanical product supplier evaluation, cost $(\mathrm{C})$, quality $(\mathrm{Q})$, on-time delivery rate $(\mathrm{T})$, purchase cost saving rate $(\mathrm{H})$, credit $(\mathrm{M})$, plus carbon footprint, form a series to describe parts characteristics (indicators) of supplier as follows:

$$
x_{i}^{\prime}=\left((C F P)_{i}, C_{i}, Q_{i}, T_{i}, H_{i}, M_{i}, \mathrm{~L}\right)
$$

Definition 2: Scheme-characteristic (indicator) matrix. The matrix that describes all characteristics (indicators) of a product's function configuration for a scheme is,

$$
\left[\begin{array}{cccc}
(C F P)_{1} & (C F P)_{2} & & (C F P)_{3} \\
C_{1} & C_{2} & & C_{n} \\
Q_{1} & Q_{2} & & Q_{n} \\
T_{1} & T_{2} & \mathrm{~L} & T_{n} \\
H_{1} & H_{2} & & H_{n} \\
M_{1} & M_{2} & & M_{n} \\
& \mathrm{~L} & \mathrm{~L} &
\end{array}\right]
$$

In the above matrix, each row represents a characteristic (indicator), each column represents the characteristic (indicator) set for a configuration scheme.

The first step is functional configuration and carbon compliance evaluation. Because suppliers are basically equivalent in product functional requirements fulfillment, product functional configuration is simplified into a problem of permutation and combination. Using exhaustive method or relevant computer software and procedures, an ideal result can be found.

The second step is comprehensive benefit evaluation. As Fig. (1) illustrates, at this stage, secondary appraisal targets should be comprehensively evaluated except for carbon footprint. The main steps are shown as follows:

- According to scheme-characteristic (indicator) matrix, we can form scheme pattern series:

$x_{i}^{\prime}=\left(C_{i}, Q_{i}, T_{i}, H_{i}, M_{i}\right) \quad(i=1,2, \mathrm{~L}, n)$

And $i$ is the scheme number.
- To form the characteristic (indicator) pattern series $x^{\prime}(k)$ , and $k$ is the number of product's characteristics (indicators). Here $k$ is 5. For instance, cost series $x^{\prime}(1)=\left(C_{1}, C_{2}, C_{3}, C_{4}, C_{5}, C_{6}\right), \quad$ quality series $x^{\prime}(2)=\left(Q_{1}, Q_{2}, Q_{3}, Q_{4}, Q_{5}, Q_{6}\right)$.

- Initializing the characteristic (indicator) pattern series $x^{\prime}(k)$

$\operatorname{INIT} x^{\prime}(k)=x(k)$

For cost series $x^{\prime}(1)$,

$$
x(1)=\left(\frac{C_{1}}{C_{1}}, \frac{C_{2}}{C_{1}}, \frac{C_{3}}{C_{1}}, \frac{C_{4}}{C_{1}}, \frac{C_{5}}{C_{1}}, \frac{C_{6}}{C_{1}}\right)
$$

Therefore, the characteristic (indicator) pattern series of scheme 1 is $x_{1}=(1,1,1,1,1)$, and the others are:

$$
x_{i}=\left(\frac{C_{i}}{C_{1}}, \frac{Q_{i}}{Q_{1}}, \frac{T_{i}}{T_{1}}, \frac{H_{i}}{H_{1}}, \frac{M_{i}}{M_{1}}\right) \quad(i=2,3, \mathrm{~L}, n)
$$

The influx of indicator's polarities is:

$$
\begin{aligned}
& Q(2), T(3), H(4), M(5) \in P_{O L}(\max ) \\
& C(1) \in P_{O L} \text { (min) }
\end{aligned}
$$

The indicator's dominating data and their initialized values are shown in Table 1.

Table 1. Dominating data and their initialized values.

\begin{tabular}{|c|c|c|}
\hline & Dominating Data & Initialized Values \\
\hline \hline$C(1)$ & $C_{\min }=\left\{C_{1}, C_{2}, \cdots, C_{6}\right\}$ & $C_{\min } / C_{l}$ \\
\hline$Q(1)$ & $Q_{\max }=\left\{Q_{1}, Q_{2}, \cdots, Q_{6}\right\}$ & $Q_{\max } / Q_{1}$ \\
\hline$T(1)$ & $T_{\max }=\left\{T_{1}, T_{2}, \cdots, T_{6}\right\}$ & $T_{\max } / T_{1}$ \\
\hline$H(1)$ & $H_{\max }=\left\{H_{1}, H_{2}, \cdots, H_{6}\right\}$ & $H_{\max } / H_{1}$ \\
\hline$M(1)$ & $M_{\max }=\left\{M_{1}, M_{2}, \cdots, M_{6}\right\}$ & $M_{\max } / M_{1}$ \\
\hline
\end{tabular}

- According to the polarities of series and by means of Dominating Principle in grey theory, the reference series $x_{0}$ is obtained.

$$
\begin{aligned}
x_{0} & =(C(1), Q(2), T(3), H(4), M(5)) \\
& =\left(\frac{C_{\min }}{C_{1}}, \frac{Q_{\max }}{Q_{1}}, \frac{T_{\max }}{T_{1}}, \frac{H_{\max }}{H_{1}}, \frac{M_{\max }}{M_{1}}\right)
\end{aligned}
$$

- By taking difference as $\Delta_{0 i}(k)=\left|x_{0}(k)-x_{i}(k)\right|$,we thus have the following difference series $\Delta_{i}(i=1,2,3, \mathrm{~L}, n)$ :

$\Delta_{i}=\left(\left|\frac{C_{\min }}{C_{i}}-C_{i}\right|,\left|\frac{Q_{\max }}{Q_{i}}-Q_{i}\right|,\left|\frac{T_{\max }}{T_{i}}-T_{i}\right|,\left|\frac{H_{\max }}{H_{i}}-H_{i}\right|,\left|\frac{M_{\max }}{M_{i}}-M_{i}\right|\right)$

$\Delta(\min )=\min _{i} \min _{k} \Delta_{0 i}(k)$

$\Delta(\max )=\max _{i} \max _{k} \Delta_{0 i}(k)$

- Calculating all schemes' grey relational coefficient and grade. 
Definition 3: Grey relational coefficient is a comparative measure between points.

$$
\gamma\left(x_{0}(k), x_{i}(k)\right)=\frac{x(\min )+\zeta x(\max )}{\Delta_{0 i}(k)+\zeta x(\max )}
$$

Where $x(\min )=\min \min \Delta_{0 i}(k)$ is lower environment parameter in $L Y_{g r}$, and $x(\max )=\max _{i} \max _{k} \Delta_{0 i}(k)$ is upper environment parameter in $L Y_{g r} \cdot \zeta \in[0,1]$, distinguishing coefficient, usually according to the principle of minimum information, $\zeta=0.5$. Set

$$
\left\{\begin{array}{l}
x(\min )=a \\
x(\max )=b
\end{array}\right.
$$

then, grey relational coefficient

$$
\gamma\left(x_{0}(k), x_{i}(k)\right)=\frac{a+0.5 \times b}{\Delta_{0 i}(k)+0.5 \times b}=\xi_{i}(k)
$$

Definition 4: By focusing the $\gamma\left(x_{0}(k), x_{i}(k)\right)$ at utter points, the algorithm on grey relational grade is as follows:

$$
\gamma\left(x_{0}, x_{i}\right)=\frac{1}{n} \sum_{k=1}^{5} \gamma\left(x_{0}(k), x_{i}(k)\right)
$$

The grey correlation grade is a comparative measure among series. Scheme is evaluated based on grey correlation grade; the scheme with the maximum value is regarded as the best.

\section{CASE STUDY}

A small reducer enterprise adopts the above-mentioned mechanical products optimal configuration algorithm based on the constraint of carbon footprint to verify the effectiveness. The assembly BOM is shown in Fig. (2).

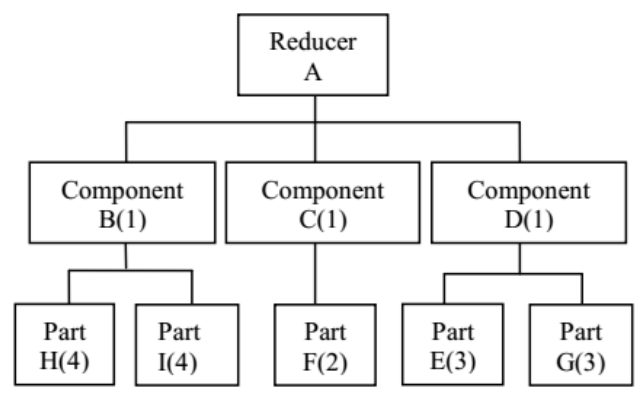

Fig. (2). BOM of the reducer.

Among the parts, $\mathrm{F}$ is manufactured by the enterprise, and E, G, H, I are provided by suppliers. The matching numbers of suppliers for them are 3,2,3,2 respectively. The index sequences for each supplier are shown in Table 2.

- Stage of function configuration. Because each supplier's parts are standard in function and interface, there are no

\begin{tabular}{|c|c|c|c|}
\hline \multirow{2}{*}{$\mathrm{E}$} & \multirow{2}{*}{3} & S3000-E & $(126,240,0.990,0.950)$ \\
\hline & & S3002-E & $(130,138,0.990,0.945)$ \\
\hline $\mathrm{F}$ & 2 & manufactured & $(65,85,0.990,0.960)$ \\
\hline G & 3 & S4001-G & $(204,370,0.995,0.965)$ \\
\hline \multirow[b]{2}{*}{$\mathrm{H}$} & \multirow[b]{2}{*}{4} & S1000-H & $(78,65,0.990,0.950)$ \\
\hline & & S1001-H & $(70,68,0.980,0.960)$ \\
\hline
\end{tabular}

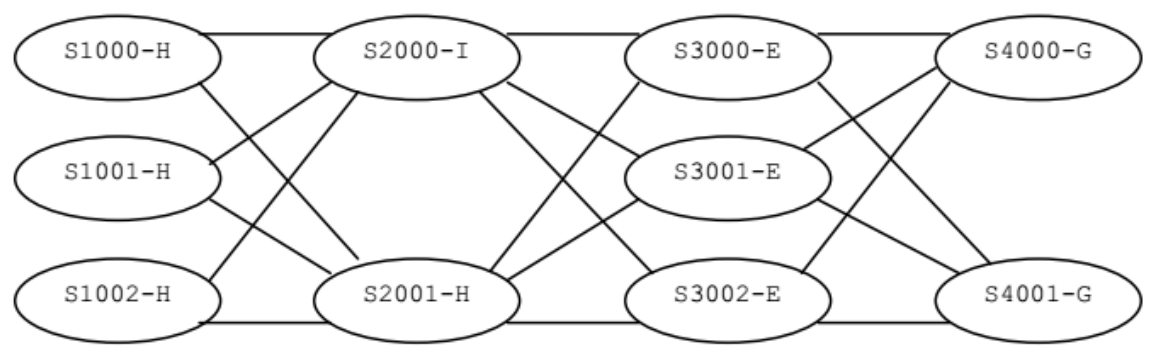

Fig. (3). Combination of suppliers.

Table 2. The index sequence lists of different suppliers. 


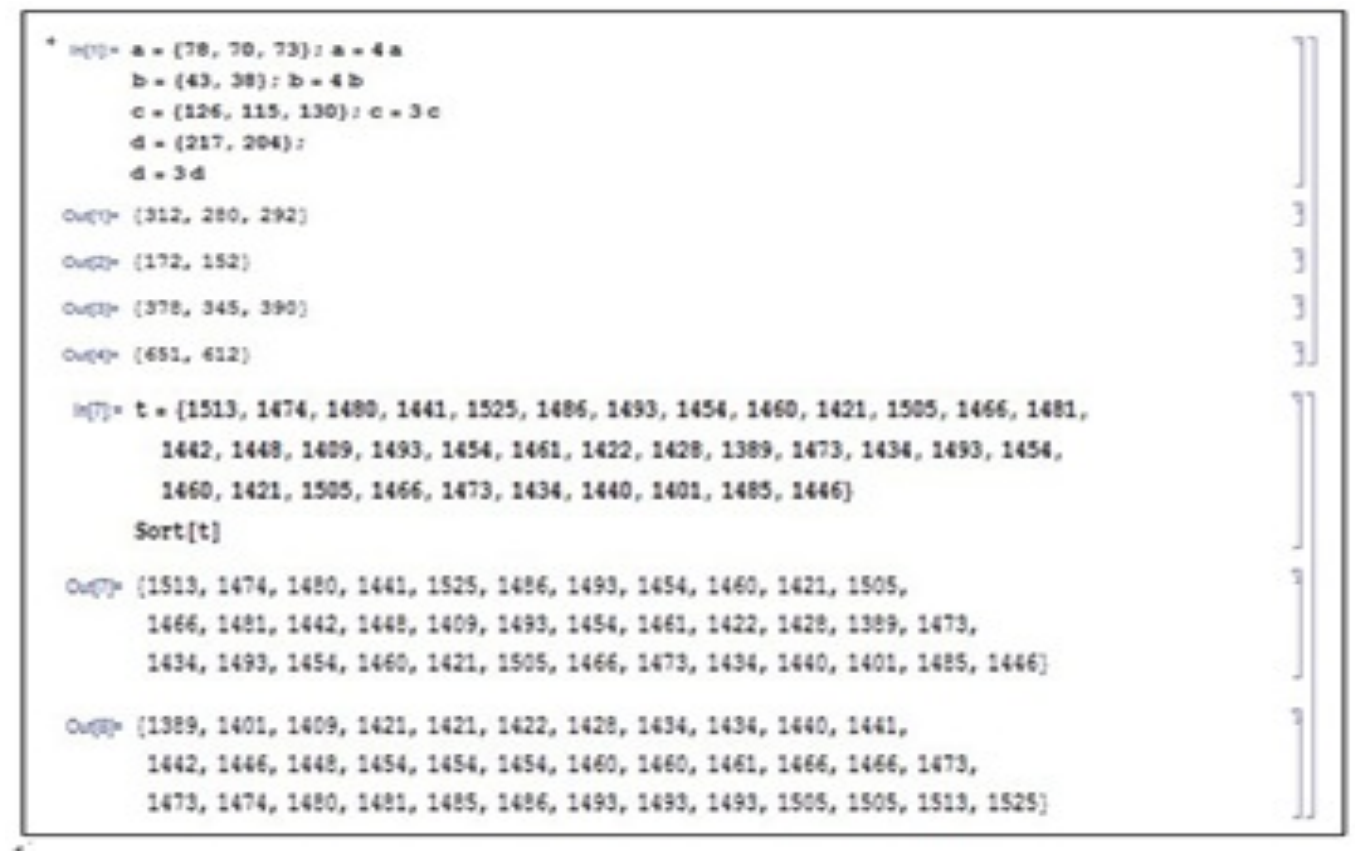

Fig. (4). Partial results' screenshot by software.

constraint conflicts. Theoretically, it is a problem of permutation and combination. Obviously, there are $3 \times 1 \times 2 \times 3 \times 2=36$ functional feasible schemes. Fig. (3) illustrates the combination of suppliers.

- Stage of compliance evaluation for carbon footprint. To find the schemes which meet the carbon footprint requirement from function feasible scheme set, namely the schemes whose total CFP satisfy $\sum C F P \leq p$.

Description of the problem: The assembly BOM has four variables, $a, b, c$, and $d$, representing four alternative carbon footprint values, respectively. It is assumed that $a$ has three options, $b$ has two options, $c$ has three options, and $d$ has two options. According to the requirement, carbon footprint of the products should be less than $1555 \mathrm{~kg}$, and the carbon footprint of $F(2)$ is $130 \mathrm{~kg}(65 \times 2)$. As a result, the total carbon footprint of other four parts cannot be more than $1425 \mathrm{~kg}, a+b+c+d \leq p$, and $p$ is $1425 \mathrm{~kg}$. For simplicity, CFP, $\mathrm{C}, \mathrm{Q}, \mathrm{T}$ are considered firstly.

$$
\text { s.t }\left\{\begin{array}{l}
a=\{78,70,73\} \\
b=\{43,38\} \\
c=\{126,115,130\} \\
d=\{217,204\} \\
a+b+c+d \leq p
\end{array}\right.
$$

Fig. (4) shows partial results' screenshot by software calculating.

According to the above result calculated, there are 6 schemes conforming to carbon footprint constraint. They are $[280,152,345,612],[292,152,345,612], \quad[280,172,345,612]$, [312,152,345,612], [292,172,345,612], [280,172,378,612].
Using [280,152,345,612] as an example, which corresponds to scheme 1, explained as follows: the scheme is configured by,

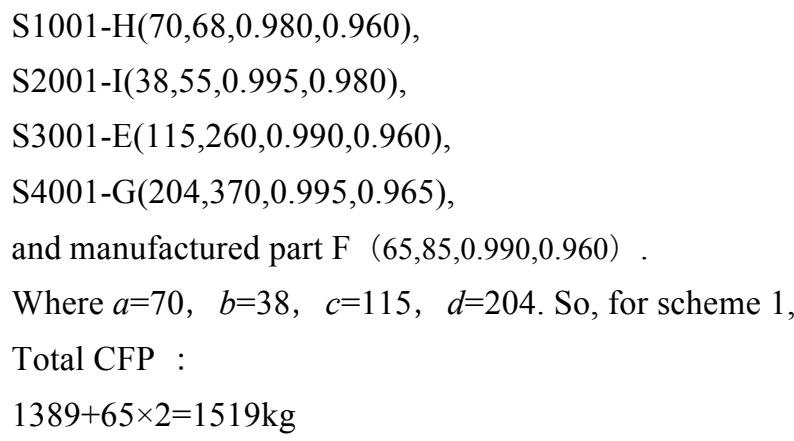

Total cost :

$4 \times 68+4 \times 55+3 \times 260+3 \times 370+2 \times 85=2552$ yuan

Total qualified ratio :

$0.980 \times 0.995 \times 0.990 \times 0.995 \times 0.990=0.8469$

Total On-Time Delivery Rate (ODR) :

$$
0.960 \times 0.980 \times 0.960 \times 0.965 \times 0.960=0.8367
$$

Using the same method to calculate the remaining data of other five schemes, adding purchase cost saving rate $(\mathrm{H})$ and credit (M), the index list of carbon footprint conformed set is shown in Table 3. At this stage, carbon footprint constraint has been satisfied, therefore no longer involved in the next comprehensive evaluation subsequently.

- The stage of optimal comprehensive evaluation. From Table 3, we can form the scheme pattern series:

Scheme 1:

$$
\begin{aligned}
x^{\prime}{ }_{1} & =\left(C_{1}, Q_{1}, T_{1}, H_{1}, M_{1}\right) \\
& =(2552,0.8469,0.8367,0.17,0.89)
\end{aligned}
$$


Table 3. Index list of CFP conformed set.

\begin{tabular}{|c|c|c|c|c|c|c|}
\hline & $\mathbf{X 1}$ & $\mathbf{X 2}$ & $\mathbf{X 3}$ & $\mathbf{X 4}$ & $\mathbf{X 6}$ \\
\hline \hline $\mathrm{C}(1)$ & 2552 & 2544 & 2532 & 2540 & 2524 & 2480 \\
\hline $\mathrm{Q}(2)$ & 0.8469 & 0.8820 & 0.7455 & 0.8820 & 0.8644 & 0.8300 \\
\hline $\mathrm{T}(3)$ & 0.8367 & 0.8539 & 0.8282 & 0.8280 & 0.8195 & 0.8195 \\
\hline $\mathrm{H}(4)$ & 0.17 & 0.12 & 0.19 & 0.21 & 0.14 & 0.16 \\
\hline $\mathrm{M}(5)$ & 0.89 & 0.92 & 0.83 & 0.87 & & 0.81 \\
\hline
\end{tabular}

Scheme 2:

$$
\begin{aligned}
x_{2}^{\prime} & =\left(C_{2}, Q_{2}, T_{2}, H_{2}, M_{2}\right) \\
& =(2544,0.8820,0.8539,0.12,0.92)
\end{aligned}
$$

Scheme 3:

$$
\begin{aligned}
x_{3}^{\prime} & =\left(C_{3}, Q_{3}, T_{3}, H_{3}, M_{3}\right) \\
& =(2532,0.7455,0.8282,0.19,0.83)
\end{aligned}
$$

Scheme 4:

$$
\begin{aligned}
x_{4}^{\prime} & =\left(C_{4}, Q_{4}, T_{4}, H_{4}, M_{4}\right) \\
& =(2540,0.8820,0.8280,0.21,0.87)
\end{aligned}
$$

Scheme 5:

$$
\begin{aligned}
x^{\prime}{ }_{5} & =\left(C_{5}, Q_{5}, T_{5}, H_{5}, M_{5}\right) \\
& =(2524,0.8644,0.8195,0.14,0.81)
\end{aligned}
$$

Scheme 6:

$$
\begin{aligned}
x^{\prime}{ }_{6} & =\left(C_{6}, Q_{6}, T_{6}, H_{6}, M_{6}\right) \\
& =(2480,0.8300,0.8195,0.16,0.80)
\end{aligned}
$$

Characteristic(indicator) pattern series:

Cost series:

$$
\begin{aligned}
x^{\prime}(1) & =\left(C_{1}, C_{2}, C_{3}, C_{4}, C_{5}, C_{6}\right) \\
& =(2552,2544,2532,2540,2524,2480)
\end{aligned}
$$

Quality series:

$$
\begin{aligned}
x^{\prime}(2) & =\left(Q_{1}, Q_{2}, Q_{3}, Q_{4}, Q_{5}, Q_{6}\right) \\
& =(0.8469,0.8820,0.7455,0.8820,0.8644,0.8300)
\end{aligned}
$$

ODR series:

$$
\begin{aligned}
x^{\prime}(3) & =\left(T_{1}, T_{2}, T_{3}, T_{4}, T_{5}, T_{6}\right) \\
& =(0.8367,0.8539,0.8282,0.8280,0.8195,0.8195)
\end{aligned}
$$

Purchase cost savings rate series:

$$
\begin{aligned}
x^{\prime}(4) & =\left(H_{1}, H_{2}, H_{3}, H_{4}, H_{5}, H_{6}\right) \\
& =(0.17,0.12,0.19,0.21,0.14,0.16)
\end{aligned}
$$

Credit series:

$$
\begin{aligned}
x^{\prime}(5) & =\left(M_{1}, M_{2}, M_{3}, M_{4}, M_{5}, M_{6}\right) \\
& =(0.89,0.92,0.83,0.87,0.81,0.80)
\end{aligned}
$$

Initializing the characteristic (indicator) pattern series $x^{\prime}(k)$, therefore $\mathrm{x}(1)=(1,0.9969,0.9921,0.9953,0.9890,0.9718)$

$\mathrm{x}(2)=(1,1.0489,0.8865,1.0489,1.0280,0.9870)$

$\mathrm{x}(3)=(1,1.0205,0.9898,0.9896,0.9795,0.9795)$

$\mathrm{x}(4)=(1,0.706,1.118,1.235,0.824,0.941)$

$x(5)=(1,1.034,0.933,0.978,0.910,0.899)$

Hence, the characteristic (indicator) pattern series of scheme 1 is $x_{1}=(1,1,1,1,1)$, and the others are:

$$
\begin{aligned}
& x_{2}=(0.9969,1.0489,1.0205,0.706,1.034) \\
& x_{3}=(0.9921,0.8865,0.9898,1.118,0.933) \\
& x_{4}=(0.9953,1.0489,0.9896,1.235,0.978) \\
& x_{5}=(0.9890,1.0280,0.9795,0.824,0.910) \\
& x_{6}=(0.9718,0.9870,0.9795,0.941,0.899)
\end{aligned}
$$

The influx of indicator's polarities are as follows:

$$
Q(2), T(3), H(4), M(5) \in P_{O L}(\max )
$$$$
C(1) \in P_{O L}(\mathrm{~min})
$$

The indicator's dominating data and their initialized values are listed in Table 4.

Table 4. Dominating data and initialized values.

\begin{tabular}{|c|c|c|}
\hline & Dominating Data & Initialized Values \\
\hline \hline$C(1)$ & 2480 & 0.97179 \\
\hline$Q(1)$ & 0.88202 & 1.04888 \\
\hline$T(1)$ & 0.85385 & 1.02021 \\
\hline$H(1)$ & 0.21 & 1.235 \\
\hline$M(1)$ & 0.92 & 1.034 \\
\hline
\end{tabular}

- According to the polarities of series and by means of Dominating Principle in grey theory, the reference series $x_{0}$ is obtained.

$$
\begin{aligned}
x_{0} & =(C(1), Q(2), T(3), H(4), M(5)) \\
& =(0.97179,1.04888,1.02021,1.235,1.034)
\end{aligned}
$$

- By taking difference as $\Delta_{0 i}(k)=\left|x_{0}(k)-x_{i}(k)\right|$,we thus have the following difference series $\Delta_{i}(i=1,2,3, \mathrm{~L}, n)$ : 


$$
\begin{aligned}
& \Delta_{1}=(0.02821,0.04888,0.02021,0.235,0.034) \\
& \Delta_{2}=(0.02508,0,0,0.529,0.006) \\
& \Delta_{3}=(0.02038,0.16237,0.03071,0.117,0.101) \\
& \Delta_{4}=(0.02351,0,0.03093,0,0.056) \\
& \Delta_{5}=(0.01724,0.02093,0.04102,0.411,0.124) \\
& \Delta_{6}=(0,0.06183,0.04102,0.294,0.135) \\
& \Delta(\min )=\min _{i} \min _{k} \Delta_{0 i}(k)=0 \\
& \Delta(\max )=\max _{i} \max _{k} V_{0 i}(k)=0.529
\end{aligned}
$$

- Calculating all schemes' grey relational coefficient and grade.

The grey relational coefficient

$$
\gamma\left(x_{0}(k), x_{i}(k)\right)=\frac{\mathrm{a}+0.5 \times b}{\Delta_{0 \mathrm{i}}(\mathrm{k})+0.5 \times \mathrm{b}}=\xi_{i}(k)
$$

Where $\mathrm{a}=0, \mathrm{~b}=0.529$.

$$
\begin{aligned}
& \xi_{1}=(0.47468,0.45771,0.48134,0.34620,0.46980) \\
& \xi_{2}=(0.47737,0.5,0.5,0.25,0.49439) \\
& \xi_{3}=(0.48146,0.38257,0.47256,0.40944,0.41984) \\
& \xi_{4}=(0.47872,0.5,0.47238,0.5,0.45214) \\
& \xi_{5}=(0.93880,0.92669,0.86573,0.39156,0.68082) \\
& \xi_{6}=(1,0.81052,0.86573,0.47359,0.66208)
\end{aligned}
$$

The grey correlation grade

$$
\begin{aligned}
& \gamma\left(x_{0}, x_{i}\right)=\frac{1}{n} \sum_{k=1}^{n} \gamma\left(x_{0}(k), x_{i}(k)\right) \\
& \xi_{1} \Rightarrow \gamma\left(x_{0}, x_{1}\right)=0.44595 \\
& \xi_{2} \Rightarrow \gamma\left(x_{0}, x_{2}\right)=0.44435 \\
& \xi_{3} \Rightarrow \gamma\left(x_{0}, x_{3}\right)=0.43318 \\
& \xi_{4} \Rightarrow \gamma\left(x_{0}, x_{4}\right)=0.48065 \\
& \xi_{5} \Rightarrow \gamma\left(x_{0}, x_{5}\right)=0.76072 \\
& \xi_{6} \Rightarrow \gamma\left(x_{0}, x_{6}\right)=0.76238
\end{aligned}
$$

That is to say,

$$
\begin{array}{llllll}
\gamma\left(x_{0}, x_{6}\right)>\gamma\left(x_{0}, x_{5}\right)>\gamma\left(x_{0}, x_{4}\right)>\gamma\left(x_{0}, x_{1}\right)>\gamma\left(x_{0}, x_{2}\right)>\gamma\left(x_{0}, x_{3}\right) \\
0.76238 & 0.76072 & 0.48065 & 0.44595 & 0.44435 & 0.43318
\end{array}
$$

According to the value of grey correlation grade, the ranking of schemes from good to bad is:

Scheme 6 , scheme 5 , scheme 4 , scheme 1 , scheme 2, scheme 3

Therefore, based on constraint of carbon footprint, the optimal configuration scheme is scheme $6[280,172,378,612]$, that means the proper suppliers are:
S1001-H(70,68,0.980,0.960),S2000-I(43,50,0.990,0.970),

S3000-E(126,240,0.990,0.950),S4001-(204,370,0.995, $0.965)$.

\section{CONCLUSION}

Through comprehensive evaluation of carbon footprint of product, core enterprises can reasonably plan product carbon footprint based on external carbon footprint constraints, according to their technology and management level. The carbon footprint controllable product means controlling carbon emissions during product development and configuration stage. It is different from traditional end-of-pipe control methods. Therefore, the control objectives can be quantified accurately and realized easily. The conclusions from this study are summarized as follows.

- The collaborative research and development framework of CFP controllable product is proposed based on LCA theory. Product configuration is the most important life cycle stage for reducing carbon footprint.

- A new three-stage theory under the constraint of carbon footprint has been proposed.

- Grey correlation analysis is verified to have a good effect in terms of comprehensive benefit evaluation for carbon footprint controllable product.

\section{CONFLICT OF INTEREST}

The author confirms that this article content has no conflict of interest.

\section{ACKNOWLEDGEMENTS}

The work was financially supported by the National Natural Science Foundation of China (Grant No. 51475434) and the Science Research Foundation of Tianjin University of Science and Technology (Grant No.20110213).

\section{REFERENCES}

[1] G. Hague, "ATKINS: Manufacturing a Low Carbon Footprint". Southborough University, UK, 2010.

[2] A. Scipioni, M. Mastrobuono, A. Mazzi, "Voluntary GHG management using a life cycle approach: A case study," Journal of Cleaner Production. vol. 18, pp. 299-306, 2010.

[3] S. Rahimifard, Y. Seow, T. Childs. "Minimizing Embodied Product Energy to support energy efficient manufacturing," CIRP AnnalsManufacturing Technology, vol. 59, pp. 25-28, 2010

[4] A.J. Alsaffar, K.R. Haapala, K.-Y. Kim, K. Okudan, E. Gül, "A process-based approach for cradle-to-gate energy and carbon footprint reduction in product design," ASME 2012 International Manufacturing Science and Engineering Conference Collocated with the $40^{\text {th }}$ North American Manufacturing Research Conference and in Participation with the Int. Conf., MSEC 2012, 2012, pp. 11411150 .

[5] B. Hong, L. Guangfu, W. Jikai. "Optimal design of products with low-carbon based on carbon footprint analysis," Journal of Computer-Aided Design and Computer Graphics, vol. 25, pp. 264-272, 2013.

[6] B. Karen, G. Dietmar, H. Jeffrey. Mastering Carbon Management Balancing Trade - offs to Optimize Supply Chain Efficiencies. IBM Global Business Services, 2668.

[7] T. Abdallah, A. Diabat, D. Simchi-Levi. "Sustainable supply chain design: A closed-loop formulation and sensitivity analysis," Production Planning and Control, vol. 23, pp. 120-133, 2012. 
[8] D.L. Ingram. "Life Cycle Assessment to Study the Carbon Footprint of System Components for Colorado Blue Spruce Field Production and Use," Journal of the American Society for Horticultural Science, vol. 138, pp. 3-11, 2013.

[9] L. Peng, H. Ji-hua, M.O. Yan-fen, "Carbon Footprint Calculation and Analysis of Accommodation Services in Four-star Hotels of Kunming,"TOURISM TRIBUNE, vol. 25, pp. 27-33, 2010.

[10] C. Jian-hui, L. Xue-min, Z. Xue-ru. "Demarcation Problems and the Corresponding Measurement Methods of the Urban Carbon Accounting," China Population Resources and Environment, vol 24, no. 4, pp. 19-25, 2014
[11] C. Sha, L. Yi-pei, C. Lei. "Data quality analysis with combination uncertainty and sensitivity for carbon footprint assessment of products," China Environment Science, vol. 34, pp. 1067-1072, 2014.

[12] A. Dormer, D.P. Finn, P. Ward, J. Cullen, "Carbon footprint analysis in plastics manufacturing," Journal of Cleaner Production, vol. 51, pp. 133-141, July, 2013.

[13] D. Julong, The Primary Methods of Grey System Theory, Wuhan, Hubei province: Huazhong University of Science and Technology Press, 2005, pp. 82-118.

(C) Bo et al.; Licensee Bentham Open.

This is an open access articles licensed under the terms of the Creative Commons Attribution-Non-Commercial 4.0 International Public License (CC BY-NC 4.0) (https://creativecommons.org/licenses/by-nc/4.0/legalcode), which permits unrestricted, non-commercial use, distribution and reproduction in any medium, provided that the work is properly cited. 